\title{
The Role of Collagen in the Aorta's Structure
}

\author{
Panagiotis Berillis*
}

Department of Ichthyology and Aquatic Environment, School of Agricultural Sciences, University of Thessaly, Nea Ionia, Magnisia, Greece

\begin{abstract}
Aorta is the largest artery in the body. Anatomically, it is traditionally divided into the ascending, the aortic arch, the descending, the thoracic and the abdominal aorta. Collagen is one of the most important components of the aortic wall. Its concentration and its total amount play a significant role in the aortas' function and mechanical properties, such as tensile strength and stiffness. The two main types of collagen found in the aorta are types I and III and they account for $80-90 \%$ of the total collagen. Age, sex hormones, aneurysms and hypertension are factors that can alter collagen and its subtypes in the aorta wall. As the aorta is a crucial artery and collagen is one of its most important components, collagen study is a helpful way to deal with aorta's abnormalities.
\end{abstract}

Keywords: Aorta, collagen, hypertension, aneurysm, sex hormones, age.

\section{INTRODUCTION}

The aorta is the largest artery in the human's and the animals' body. Its role is to distribute oxygenated blood to all parts of the body through the systemic circulation. The cardiovascular system is affected by the function of the aorta in many ways. When the stiffness of the aorta is increased, an increased pulse-wave velocity is induced. It causes premature return of reflected pulse waves in late systole. It also increases central pulse load and the myocardial demand of oxygen [1].

Aorta is usually divided into five sections: a) the ascending aorta, b) the arch of aorta, c) the descending aorta, d) the thoracic aorta and e) the abdominal aorta (Fig. 1). The ascending aorta is the section between the heart and the arch of aorta. The peak part is the arch of aorta which looks somewhat like an inverted "U". The descending aorta, the section from the arch of aorta to the point where it divides into the common iliac arteries, is divided in two parts: the thoracic and the abdominal aorta. Thoracic aorta is the part of the descending aorta above the diaphragm, while abdominal aorta is the part below the diaphragm.

The aortic wall is divided into the adventitia layer, the media layer and the intima layer (Fig. 1). It contains collagen fibrils, smooth muscle cells, and elastic fibers as the primary load-bearing components [2]. The elastin forms elastic lamellae, which is situated between the smooth muscle cells. Collagen surrounds the smooth muscle cells and the elastic lamellae. Both collagen and elastin are crucial for the determination of the tensile strength and the stiffness of the aorta [3]. Although collagen is a key element of the extracellular matrix of the aorta and its removal is capable of reducing the local stiffness by up to 50 times, the remaining aorta tissue is still capable to form a coherent network [4].

*Address correspondence to this author at the Department of Ichthyology and Aquatic Environment, School of Agricultural Sciences, University of Thessaly, Nea Ionia, Magnisia, Greece; Tel/Fax: 302421093248;

E-mail: pveril@uth.gr
The mechanical properties of the aorta are depended not only on the amounts of the aortic wall main constituents but also on the spatial organization and the mechanical interactions among these components. These interactions may be mediated by extracellular matrix adhesion proteins and their membrane receptors [5]. The most important mechanical property of the aortic wall is its non-linear elasticity [6]. Wells et al. [7] reported changes in mechanical properties and collagen cross-linking of the ovine thoracic aorta during perinatal development and postnatal maturation. One of the most common mechanical properties which are used to describe the behavior of an elastic material is the elastic modulus. The aortic tissue is a non linear material and the elastic modulus does not represent the continuously varying response of the tissue. The incremental modulus, the differentiation of the stress-strain relationship, has been proposed to take into account the variation of the elastic modulus $[8$, 9].

\section{COLlageN}

Collagen is a group of naturally occurring proteins. It is one of the long, fibrous structural proteins whose functions are different from those of globular proteins such as enzymes. It is abundant in most invertebrates and vertebrates $[10,11]$. It is the main protein of the connective tissue and represents about one-fourth of the total protein content in many animals [12]. The collagen molecule is formed by three polypeptide strands, named alpha chains. Each chain possesses the conformation of a left-handed helix. These three helices are twisted together to form a triple helix which is stabilized by hydrogen bonds. Several reports on invertebrates' collagen have emphasized its morphological and functional characteristics [13-15]. There is some covalent cross-linking within the triple helices. Also there is a variable amount of covalent cross-linking between the collagen molecule helices. That way well-organized aggregates, such as fibrils, are forming [16]. Collagen fibrils are the aggregation of several subunits, called tropocollagen. Tropocollagen is approximately $300 \mathrm{~nm}$ long and $1.5 \mathrm{~nm}$ in diameter. These 

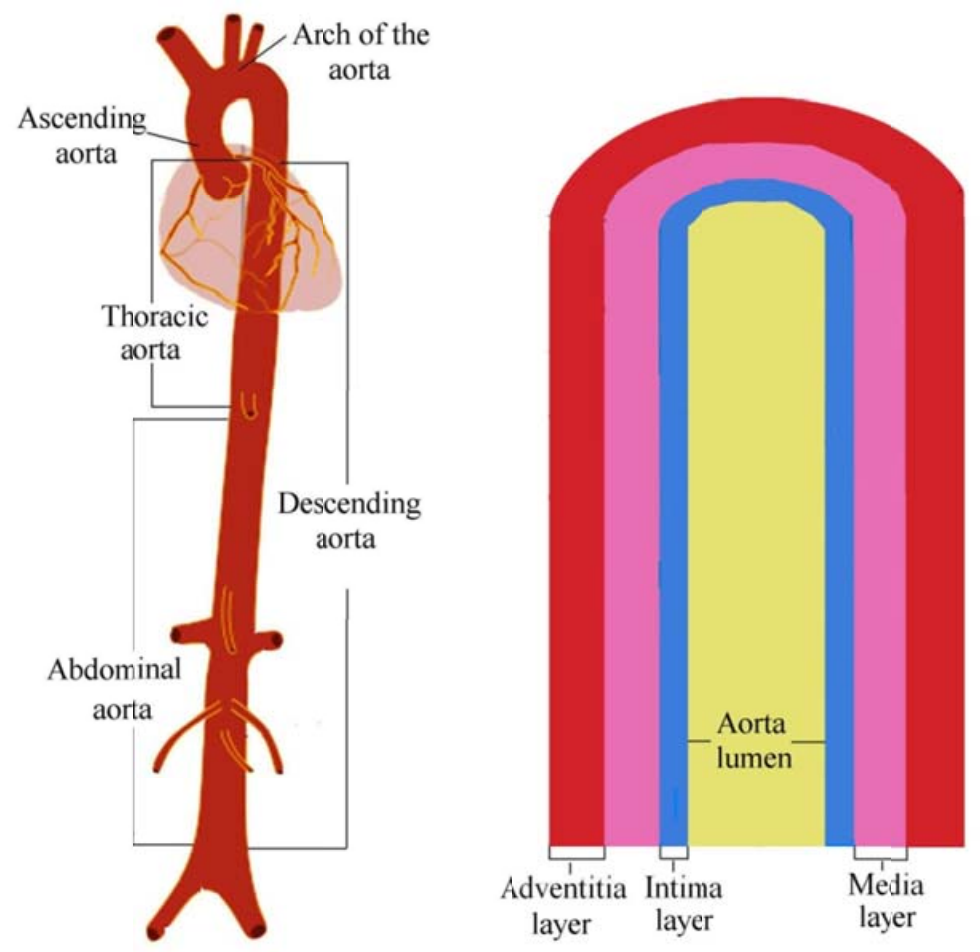

Fig. (1). The five sections of the aorta and the aortic wall layers.

fibrils are semi-crystalline aggregates of collagen molecules. Collagen fibers are bundles of fibrils. These fibers are a major component of the extracellular matrix that supports most tissues and provides structure to the cells from the outside. Collagen exists in many places throughout the body (skin, bones, liver, aorta, muscles etc). So far, 29 types of collagen have been identified and described. However, over $90 \%$ of the collagen in the body is of type I, II, III, and IV. Type I is the most abundant collagen type in vertebrates' tissues (about $22 \%$ of the total protein in vertebrates is collagen type I). Its a-chain is formed by two a1(I) and one a 2 chains ([a1(I) $\left.]_{2} \mathrm{a} 2\right)$. It can be found in skin, liver, bones, aorta, cornea and other tissues. Type II and type III are formed by three a-chains of the same type $\left(\mathrm{a} 1[\mathrm{II}]_{3}\right.$ and $\mathrm{a} 1[\mathrm{III}]_{3}$ respectively). Type-II collagen is the basis for articular cartilage and hyaline cartilage. Type III structurally is quite similar with type I. It represents the $5-20 \%$ of the total collagen in mammals' tissues such as skin, bones, and aorta. Type-IV collagen chain formation is [a1(IV) $]_{2} \mathrm{a} 2$ (IV) and is found primarily in the basal lamina [17].

The characteristic banded appearance of collagen fibrils has been known since the early days of electron microscopy. The most striking feature of the fibrils is the regular transverse banding with its axial periodicity, named D-period, which is about $68 \mathrm{~nm}[18,19]$. There is a $40 \mathrm{~nm}$ distance between tropocollagen molecules of the same line (Fig. 2), while subsequent lines have been moved by $68 \mathrm{~nm}$. Tropocollagen molecules forming the collagen fibrils are not located exactly below each other. This is because the length of the tropocollagen, which is $300 \mathrm{~nm}$, divided by the axial periodicity (D-period $=68 \mathrm{~nm}$ ) does not give an integer number.

When the collagen fibrils are exposed to solutions of heavy metal salts, up to 12 staining bands (Fig. 3) of differing widths can be distinguished in each D-period [20, 21]. In fibrils prepared for electron microscopy, dehydration leads to low values of D-period. The D-period and the fibril diameter of the collagen have been studied in many tissues in order to determine how the collagen affiliates with tissue disorders or how it affects the mechanical properties of these tissues [2225].

\section{AORTIC COLLAGEN}

The two main types of collagen found in the aorta are types I and III. They account for $80-90 \%$ of the total collagen present in the aorta [2, 26-28]. Types IV, V, VI and VIII can be also found in smaller amounts [28]. In the normal aorta, fibrillar collagens (types I and III) are the major constituents of the intima, media, and adventitia layer. Types IV and $\mathrm{V}$ of collagen are situated in the endothelial and smooth muscle cell basement membranes [29], along with collagen types I and III [30]. According to Silver et al. [2], the presence of type III collagen in aortic wall increases the flexibility of the collagen fibrils. Other studies [27] demonstrate the integral role of type I collagen in the biomechanical and functional properties of the aorta. Howard [31] localized immunocytochemically the collagen types I, III and IV in fetal bovine aorta. In the ascending region of the aorta, types I, III, and IV colocalized in the intima and media layers. In the descending thoracic aortic region types I and IV were distributed throughout the intima and media layers, whereas type III collagen localization was variable depending on the antibody used for detection. In the abdominal aorta types I and IV collagen were found in the intima and media layers. Type III collagen localized heavily to the adventitia layer. Murata [32] referred that the amounts of collagen type I, III and $\mathrm{V}$ per $1 \mathrm{~g}$ of defatted dry weight in the intima of human aorta are $69 \mathrm{mg}, 18 \mathrm{mg}$ and $15 \mathrm{mg}$ respectively. In the media these amounts are $51 \mathrm{mg}, 22 \mathrm{mg}$ and $12 \mathrm{mg}$, Adventitia has the largest amount of type I collagen $(91 \mathrm{mg})$. Types III and V 


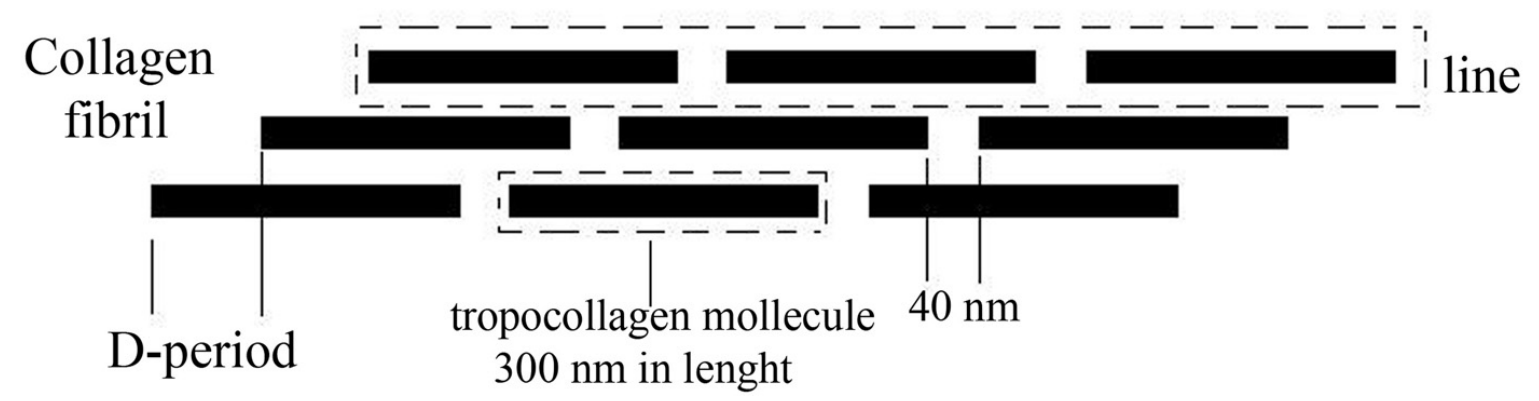

Fig. (2). Axial structure of D-periodic collagen fibril.



Fig. (3). An electron micrograph of a collagen fibril positively stained with phosphotungstic acid and uranyl acetate. The characteristic banding appearance repeats regularly in the direction of the fibril axis with a periodicity D. Up to 12 staining bands of differing widths per Dperiod can be distinguished. Labeling of the bands follows the notation of Hodge and Schmitt [17, 21].

are represented in this layer by $14 \mathrm{mg}$ and $8 \mathrm{mg}$ respectively. There is only one study that investigates the ultrastructure of collagen fibrils in the aorta [22]. The descending aorta of male Wistar rats of different ages ( 2 months, 4 months and 14 moths old) was studied under a transmission electron microscope and the diameter of the collagen fibrils was measured $(81.7 \pm 7.6 \mathrm{~nm}, 83.3 \pm 5.9 \mathrm{~nm}$ and $80.1 \pm 6.4 \mathrm{~nm}$ respectively). Collagen fibrils appeared to be packed in a roughly parallel array (Fig. 4). The aorta's collagen fibrils Dperiod can be measured using a transmission electron microscope and image analysis programs [17]. It is appeared to be similar with the D-period of other tissue's collagen. Most of the mature collagen molecules in blood vessels and arteries are known to be cross-linked together by the action of lysyl oxidase [33, 34]. Intermolecular cross-links are located probably between a segment near the C-terminal of a molecule and a segment near the N-terminal of another molecule [33]. These cross-links stabilize the collagen fibrils and provide stiffness to the vessels. Another study [35] demonstrates the integral role of type I collagen in the biomechanical and functional properties of the aorta and reveal that the presence of homotrimeric type I collagen isotype (absence of $\alpha 2(\mathrm{I})$ collagen) significantly weakens the aorta.

Collagen probably is one of the most important components of the aortic wall. The amount of collagen and the collagen types ratios in the aortic wall can change with ageing, influence of sex hormones and pathology (aneurysms, hyper- 

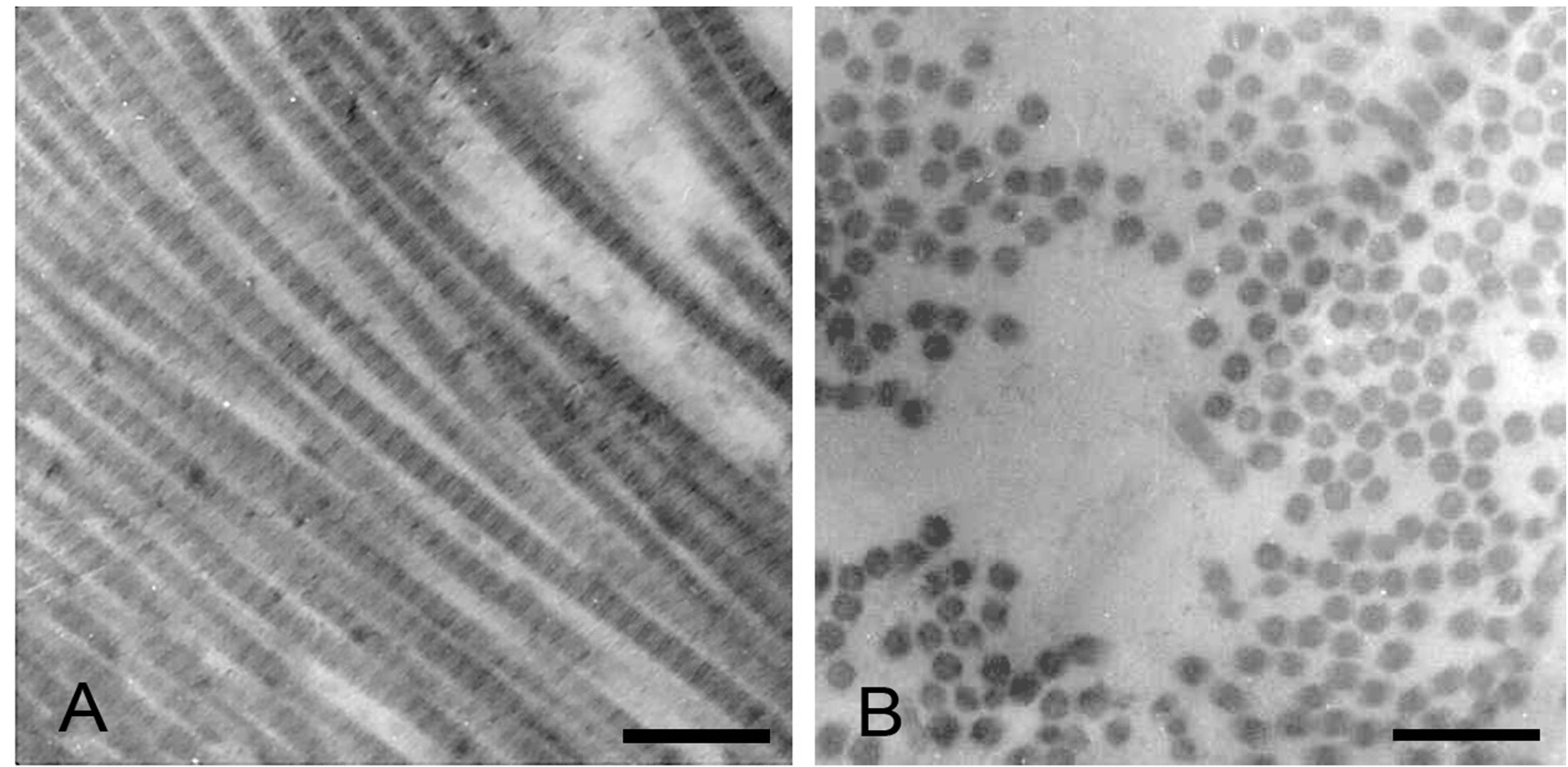

Fig. (4). A. Collagen fibrils in the descending aorta of male Wistar rats' aorta appeared to be packed in a roughly parallel array. Bar=0.6 $\mu$ m. B. Aorta's collagen fibrils diameter can be measured by the use of a transmission electron microscope. Bar $=0.35 \mu \mathrm{m}$ [17].

tension). For example, with aging, the aortic wall becomes stiffer. This could happen due to changes in wall stress or composition. According to Cantini et al. [36] a change in the composition of the wall is responsible for the age-linked increase in wall stiffness while the elastin/collagen ratio does not change with age. The study of collagen provides a unique opportunity to see normal and abnormal aorta from another point of view.

\section{A. Age-related Changes in Amount and Concentration of Collagen}

Aorta's biomechanical and functional properties are changing with ageing. During the ageing process collagen and elastin contents in the aortic wall show a very significant loss of extracellular matrix structure [37]. The aorta's stiffness is also increased during ageing [42] and an increment in collagen content [37-39] take place. Cattell [37] reported that the collagen concentration in the wall of the thoracic aorta (ascending aorta and descending arch) was increased with age over the 14-90 year range, while the amount of the collagen was decreased. At the age of 90 years the thoracic aorta's collagen concentration was $72 \%$ more than at the age of 14 years. The amount of collagen was decreased by $80 \%$ at the age of 90 years. The correlation between collagen concentration and age was depended by the thoracic aorta part (relatively weak for the ascending aorta, stronger for the descending arch and best for the area close to the diaphragm). Cattell suggested that the loss of other aortic wall components with ageing was more acute closer to the diaphragm. Andreotti [38] studied human aortas from subjects aged from 9 to 84 years. He reported that ageing was accompanied by an increment in collagen content. Collagen concentration did not seem to change significantly up to the age of 50, but was increased thereafter [37, 40]. Maurel [41] during his study with aortic arch, thoracic aorta, upper abdominal and lower abdominal aorta reported no variation of collagen content with ageing. This discrepancy may be due to the use of cyanogen bromide digestion that authors used in order to release peptides for estimation. Cyanogen bromide may be less effective on older tissue. Maurel also found that with ageing collagen type III decreased in quantity from the heart to the distal portion of the aorta. Bruel [42] reported a decrement in the amount of collagen type I relative to type III in rats aorta during the ageing process. The total amount of collagen was not changed, but the increment in the aorta diameter resulted in less collagen per $\mathrm{mm}^{2}$ of the aortic wall. Other studies showed no changes or a slight increment in collagen and elastin concentration in relation to age [43-46].

\section{B. Influence of Sex Hormones on Aorta's Collagen}

Aorta abnormalities (abdominal aneurysm and atherosclerotic vascular disease) seem to be more common in men than woman. The risk of an abdominal aorta aneurysm appearance in men is 4 times higher than in women [47]. Scott suggests [48] that the prevalence of an abdominal aortic aneurysm in women is six times lower than in men. Women before menopause have a lower incidence of atherosclerotic vascular disease than do men of the same age [49]. The incidence in women after menopause starts to approach that of men $[50,51]$. The correlation between sex hormones and collagen (one of the most important components of the aortic wall) studied by many researchers. These studies showed a strong correlation between sex hormones and aorta's collagen [50-53]. Collagen synthesis and accumulation also found to be increased in atherosclerotic blood vessels $[52,53]$. Cembrano [50] estimated aorta's collagen in normal chickens of both sexes, in cockerels gonadectomized or treated with estradiol and in hens treated with testosterone. The results showed a significantly higher amount of collagen in males than in females. Collagen values of the gonadectomized males and males treated with estradiol were similar with those of the females. When the females were treated 
with testosterone the collagen values were similar with those of the males. Fischer studied extensively the influence of sex hormones on aorta's collagen [51-53]. He founds that castrated rats receiving testosterone had significantly higher total collagen than those receiving estradiol [51]. Estradiol in the presence or absence of testosterone can decrease the total accumulation of vascular connective tissue and may alter the proportions of collagen thus the vessel can be more distensible [51]. Testosterone had an opposite but a less marked effect than estradiol on vascular connective tissue. Similar results were found when rabbits were used as experimental animals [53]. The administration of estradiol to ovariectomized rabbits resulted in a degree of atherosclerosis and collagen synthesis similar to that of intact rabbits. However, ovariectomized rabbits administered progesterone resembled the ovariectomized rabbits without hormone replacement. The results of another study [52] indicated that testosterone and probably progesterone exert an anabolic effect on arterial connective tissue metabolism in rabbits, increasing the synthesis of collagen and resulting in increased accumulation of collagen in the female atherosclerotic aorta. Fischer findings are consistent with the hypothesis that sex hormones can affect the development of atherosclerosis. Specifically, testosterone and progesterone favored the development of atherosclerosis.

\section{Aortic Aneurysms and Collagen}

Aneurysm is an abnormal and persistent dilatation of a vessel. A common site for aneurysm formation is the abdominal part of the aorta. Collagen appears to play an important role in the aortic aneurysms. Collagen turnover is important for vessel wall repair and regeneration and its degradation is believed to be associated with the rapture of an abdominal aortic aneurysm $[54,55]$.There are studies reporting that the total amount of collagen is increased in aneurysmal aorta. Whittle [56] examined the dissecting aneurysms. Aortic sites which actually involved in dissection were compared with the corresponding sites in controls. They came to the conclusion that in the case of the dissecting aneurysms there was a highly significant increment in the amount of collagen and a significant decrement in the collagen concentration. This made the aortic wall weaker and less able to withstand the mechanical stresses constantly imposed upon it. The results of the above study agreed with Menashi and Rizzo [50, 51] who studied abdominal aortic aneurysm. In Menashi's study [57] there was an increment in the proportion of collagen in aneurysmal aorta from $62 \%$ to $84 \%$ and it appeared to be the result of preferential elastin degradation. Rizzo [58] found that in aneurysms the collagen was increased from $24 \% \pm 5 \%$ to $37 \% \pm 16 \%$ while elastin was decreased from $12 \% \pm 7 \%$ to $1 \% \pm 1 \%$. Carmo [59] refers that beside the confirmed decreased elastin content in aneurysmal walls there is also a concurrent increment of collagen cross-links. They concluded that since the total collagen markers were decreased, it is reasonable to suggest that in aneurysmal aortic walls old collagen accumulates cross-links while new collagen biosynthesis is somehow defective.

In contrast Borges [60] refers that collagen is reduced and disrupted in human aneurysms and dissections of ascending aorta. In his study aortic dissections and aneurysms showed a decrement in collagen content that could be related to a weakness of the wall underlying the diseases.

The ratio of type I to type III collagen was also suggested to be important in aortic aneurysms. Menashi [57] estimated that this ratio did not vary significantly from $2: 1$ in both control and aortic aneurysms groups. A subgroup of three patients with a significant family history of aneurysm had lower amounts of type III collagen in the aortic media, suggesting that abnormalities in type III collagen may be due to the genetic factors contributing to familial clustering of aneurysms. Rizzo [58] estimated that collagen type I accounted for $74 \% \pm 4 \%$ of aneurysm and $73 \% \pm 4 \%$ of control. Collagen type III accounted for $26 \% \pm 4 \%$ of aneurysm and $27 \%$ $\pm 4 \%$ of control.

\section{Hypertension and Aortic Collagen}

Hypertension is associated with structural alterations of conduit arteries, and arterial wall hypertrophy is a major feature of these changes. Hypertension appears to be one type of insult that enhances vascular connective tissue formation and induced an increased collagen synthesis and an increased total amount of collagen [61-66]. Wolinsky [61] studied the long-term effects of hypertension on the aortic wall of male Carworth rats. Hypertension was produced by clipping the renal artery. In general, renovascular hypertension is associated with excessive collagen and elastin deposition [65]. Comparison between control and hypertensive aortas at 2.5 and 16 months old rats showed significant increments in absolute amounts of both elastin and collagen. The percent of collagen increased sharply in aortas of both control and hypertensive rats over the period from 2.5 to 16 months. Interestingly sharp increases in absolute amount of both collagen and elastin were seen in ageing controls as well. The collagen percent in hypertensive vessels was less than the 16 months controls. Wolinsky [61] came to the conclusion that the aortic wall response to increases in tension resulting from increments in blood pressure and diameter. The ageing association was similar to that seen with over the hypertension. Ooshima [62] came to the same conclusion of the significant increment in absolute collagen amounts in hypertensive aortas by studying collagen synthesis in Wistar rats' blood vessels. Hypertension appears to be the type of insult that enhances vascular connective tissue formation. According to Ooshima [62] the largest increment in collagen biosynthesis was observed in the aorta, which in most species is particularly susceptible to atheroma formation. The increment of vascular collagen biosynthesis that is brought on by physical or chemical insults to the vascular system may be compared to the increments in collagen formation brought on by insult or injury to the most of tissues. The observed thickening and changes in elasticity of blood vessels in hypertension may be explained by the increased collagen biosynthesis. In the early phase of hypertension there are increased aortic collagen and elastin contents, which are associated with vascular hypertrophy [66]. Increased collagen biosynthesis may also be an early indicator of the vascular hypertension-induced lesions. In the aorta of spontaneously hypertensive rats, the collagen concentration was decreased approximately $16 \%$, but the collagen synthesis was about twofold higher [63]. In the same study the passive mechanical properties of the aortas showed that in spontaneously hypertensive rats the aortas were stiffer compared with aortas of normotensive rats. Hy- 
pertension does not affect collagen content of the entire aorta evenly. In the abdominal part the collagen content seems to be unaffected by hypertension. However in the arch and in the descending thoracic part, hypertension is associated with an increment in collagen content [64].

Different collagen types appear to be affected by hypertension. Type $\mathrm{V}$ collagen represented a minor fraction of total collagen (about 5\%) in the aortas. Bashey [63] showed that in hypertensive rats this fraction (collagen type V) was twofold greater than in normotensive rats. This increment was accompanied by a reduction in the proportion of type I collagen but with no change in the proportion of type III. In genetically hypertensive rats, the wall stiffness of the large arteries is not affected by hypertension itself only, but also by differences in the contents of collagen subtypes. Higher density of collagen III but not of collagen I was demonstrated in conduits arteries of rats with genetic hypertension [67]. According to Herrmann [68] in hypertension aorta's collagen III production is associated with the transformation of adventitial fibroblasts into myofibroblasts. It has also been proposed that the loss of collagen from the vessel wall may be accompanied by a greater loss of other vascular components leading to an overall increase in collagen concentration [69].

\section{CONCLUSIONS}

Aorta is the most crucial artery in humans and animals. Its abnormal function is associated with many cardiovascular abnormalities. Collagen, especially type I and III, is one of the most important aortic wall components and it can be affected by many factors, such as ageing process, sex hormones, hypertension and aneurysms. With ageing, aorta becomes stiffer, there is a loss of its total collagen amount, an increment of the collagen concentration and aortic collagen subtypes are affected. Men are more likely than women to be insulted by aorta abnormalities. The risk of an abdominal aorta aneurysm appearance in men is 4 times higher than in women. There is a strong correlation between sex hormones and aorta's collagen. Sex hormones can affect the development of atherosclerosis. Estradiol can decrease the total accumulation of vascular connective tissue and may alter the proportions of collagen thus the vessel can be more distensible. Testosterone has an opposite but a less marked effect than estradiol on vascular connective tissue. Aortic collagen is also important in cases of aortic aneurysms and hypertension. Its degradation believed to be associated with the rapture of abdominal aortic aneurysm. In the case of dissecting aneurysms collagen amount shows an increment, while collagen concentration shows a decrement. The ratio of type I to type III collagen is also appeared to play an important role in aortic aneurysms. The excessive collagen and elastin deposition is associated with renovascular hypertension. There is a significant increment in absolute collagen amounts in hypertensive aortas and the increased collagen biosynthesis may be an early indicator of the vascular lesions brought on by the hypertension. Different aortic collagen types appear to be also affected by hypertension.

\section{CONFLICT OF INTEREST}

The author confirms that this article content has no conflicts of interest.

\section{ACKNOWLEDGEMENTS}

The author thanks Mente Elena and Kormas Kostas for their helpful comments.

\section{REFERENCES}

[1] Laurent, S.; Cockcroft, J.; Van Bortel, L.; Boutouyrie, P.; Giannattasio, C.; Hayoz, D.; Pannier, B.; Vlachopoulos, C.; Wilkinson, I.; Struijker-Boudier, H. Expert consensus document on arterial stiffness: methodological issues and clinical applications. Eur. Heart J., 2006, 27, 2588-2605.

[2] Silver, F. H.; Horvath, I.; Foran, D. J. Viscoelasticity of the vessel wall: the role of collagen and elastic fibers. Crit. Rev. Biomed. Eng., 2001, 29, 279-301.

[3] Bruel, A.; Oxlund, H. Growth hormone influences the content and composition of collagen in the aorta from old rats. Mech. Ageing Dev., 2002, 123, 627-635.

[4] Beenakker, J. W. M.; Ashcroft, B.A.; Lindeman, J.H.N.; Oosterkamp, T.H. Mechanical properties of the extracellular matrix of the aorta studied by enzymatic treatments. Biophys. J., 2012, 102, 1731-1737.

[5] Bezie, Y.; Daniel-Lamaziere, J. M.; Gabella, G.; Koffi, I.; Laurent, S.; Lacolley, P. Molecular and cellular determinants of arterial stiffness: role of cell-matrix connections. Pathol. Biol., 1999, 47, 669-676.

[6] Shadwick, R. E. Mechanical design in arteries. J. Exp. Biol., 1999, 202, 3305-3313.

[7] Wells, S. M.; Langille, B. L.; Lee, J. M.; Adamson, S. L. Determinants of mechanical properties in the developing ovine thoracic aorta. Am. J. Physiol., 1999, 277, 1385-1391.

[8] He, C. M.; Roach, M. R. The composition and mechanical properties of abdominal aortic aneurysms. J. Vasc. Surg., 1994, 20, 6-13.

[9] Xiong, J.; Wang, S. M.; Zhou, W.; Wu, J. G. Measurement and analysis of ultimate mechanical properties, stress-strain curve fit, and elastic modulus formula of human abdominal aortic aneurysm and nonaneurysmal abdominal aorta. J. Vasc. Surg., 2008, 48, 189195.

[10] Adams, E. Invertebrate collagens. Marked differences from vertebrate collagens appear in only a few invertebrate groups. Science 1978, 202, 591-598.

[11] Gallop, P.M. and Paz, M.A. Posttranslational protein modifications, with special attention to collagen and elastin. Physiol. Rev., 1975, $55,418-487$.

[12] Bailey, A. The nature of collagen. Compr. Biochem., 1968, 26, 297-424.

[13] Gosline, J. M. Connective tissue mechanics of metridium sensile. I. Structural and compositional aspects. J. Exp. Biol., 1971, 55, 763775.

[14] Engel, J. Versatile collagens in invertebrates. Science 1997, 277, 1785-1786.

[15] Bairati, A.; Gioria, M. Collagen fibrils of an invertebrate (Sepia officinalis) are heterotypic: immunocytochemical demonstration. $J$. Struct. Biol., 2004, 147, 159-165.

[16] Perumal, S.; Antipova, O.; Orgel, J.P. Collagen fibril architecture, domain organization, and triple-helical conformation govern its proteolysis. Proc. Natt. Acad. Sci, 2008, 105, 2824-2829.

[17] Berillis, P. Effect of lithium to collagen of various tissues. Use of electron microscopy and image analysis. $\mathrm{PhD}$ Thesis, University of Ioannina: 2004.

[18] Miller, A. Molecular packing in collagen fibrils. In: Biochemistry of Collagen, Ramachandran, G.N., Reddi, A.H., Eds.; Plenum Press, New York, 1976; pp. 85-136.

[19] Brodsky, B.; Eikenberry, E. F. Characterization of fibrous forms of collagen. Methods Enzymol., 1982, 82, 127-174.

[20] Chapman, J. A. The staining pattern of collagen fibrils. I. An analysis of electron micrographs. Connect. Tissue Res., 1974, 2, 137150 .

[21] Hodge, A. J. and Schmitt, F. O. The charge profile of the tropocollagen macromolecule and the packing arrangement in native-type collagen fibrils. Proc. Natt. Acad. Sci, 1960, 46, 186-197.

[22] Tzaphlidou, M.; Berillis, P. Effect of lithium administration on collagen and breaking pressure of the rat thoracic descending aorta. J. Trace. Elem. Exp. Med., 2004, 17, 151-160. 
[23] Tzaphlidou, M.; Berillis, P. Collagen fibril diameter in relation to bone site. A quantitative ultrastructural study. Micron., 2005, 36, 703-705.

[24] Zervakis, M.; Gkoumplias, V.; Tzaphlidou, M. Analysis of fibrous proteins from electron microscopy images. Med. Eng. Phys., 2005, 27, 655-667.

[25] Berillis, P.; Emfietzoglou, D.; Tzaphlidou, M. Collagen fibril diameter in relation to bone site and to calcium/phosphorus ratio. Sci. World J., 2006, 6, 1109-1113.

[26] Treska, V.; Topolcan, O.; Kocova, J.; Pecen, L.; Tonar, Z. Type I and III procollagen in patients with abdominal aorta aneurysms. Cas. Lek. Cesk., 1999, 138, 142-146.

[27] Vouyouka, A.G.; Pfeiffer, B.J.; Liem, T. K.; Taylor, T.A.; Mudaliar, J.; Phillips, C. L. The role of type I collagen in aortic wall strength with a homotrimeric [a1(I)]3 collagen model mouse. $J$. Vasc. Surg., 2001, 33, 1263-1270.

[28] Kielty, C. M.; Hopkinson, I.; Grant, M.E. In: Connective tissue and its heritable disorders, Royce, P.M.: Steinmann, B., Eds.; John Wiley: New York, 1993; pp. 103-147.

[29] Shekhonin, B. V; Domogatsky, S. P.; Muzykantov, V. R.; Idelson, G. L.; Rukosuev, V. S. Distribution of type I, III, IV, and V collagen in normal and atherosclerotic human arterial wall: immunomorphological characteristics. Coll. Relat. Res., 1985, 5, 355-368.

[30] Mills, A. N.; Haworth, S. Pattern of connective tissue development in swine pulmonary vasculature by immunocalization. J. Pathol., 1987, 153, 171-176.

[31] Howard, P.; Macarak, E. Localization of collagen types in regional segments of the fetal bovine aorta. Lab. Invest., 1989, 61, 548.

[32] Murata, K.; Motayama, T.; Kotake, C. Collagen types in various layers of the human aorta and their changes with the atherosclerotic process. Atherosclerosis, 1986, 60, 251-262.

[33] Eyre, D. R.; Paz, M.A.; Gallop, P. M. Cross-linking in collagen and elastin. Annu. Rev. Biochem., 1984, 53, 717-748.

[34] Last, J. A.; Armstrong, L. G.; Reiser, K. M. Biosynthesis of collagen crosslinks. Int. J. Biochem., 1990, 22, 559-564.

[35] Vouyouka, A.G.; Pfeiffer, B. J.; Liem, T. K.; Taylor, T. A.; Mudaliar, J., Phillips, C. L. The role of type I collagen in aortic wall strength with a homotrimeric [a1(I)]3 collagen model mouse. $J$. Vasc. Surg., 2001, 33, 1263-1270.

[36] Cantini, C.; Kieffer, P.; Corman, B.; Liminana, P.; Atkinson, J.; Lartaud-Idjouadiene, I. Aminoguanidine and aortic wall mechanics, structure, and composition in aged rats. Hypertension, 2001, 38, 943-948.

[37] Cattell, A. M.; Anderson, J. C.; Hasleton, P. S. Age-related changes in amounts and concentrations of collagen and elastin in normotensive human thoracic aorta. Clin. Chim. Acta., 1996, 245, 73-84.

[38] Andreotti, L.; Busotti, A.; Cammelli, D.; di Giovine, F.; Sampognaro, S.; Sterrantino, G.; Varcasia, G.; Arcangeli, P. Aortic connective tissue in ageing -- a biochemical study. Angiology, 1985, 36, 872-879.

[39] Hosoda, Y.; Kawano, K.; Yamasawa, F.; Ishii, T.; Shibata, T.; Inayama, S. Age-dependent changes of collagen and elastin content in human aorta and pulmonary artery. Angiology, 1984, 35, 615621.

[40] Myers, V. C; Lang, W.W. Some chemical changes in the human thoracic aorta accompanying the aging process. J. Gerontol., 1946, 1, 441-444.

[41] Maurel, E.; Shuttleworth, C.A.; Bouissou, H. Interstitial collagens and ageing in human aorta. Virchows Arch., 1987, 410, 383-390.

[42] Bruel, A.; Oxlund, H. Changes in biomechanical properties, composition of collagen and elastin, and advanced glycation endproducts of the rat aorta in relation to age. Atherosclerosis, 1996, 127, $155-165$.

[43] Vogel, H. G. Influence of maturation and age on mechanical and biochemical parameters of connective tissue of various organs in the rat. Connect. Tissue Res., 1978, 6, 161-66.

[44] Berry, C. L.; Greenwald, S.E. Effects of hypertension on the static mechanical properties and chemical composition of the rat aorta. Cardiovasc. Res., 1976, 10, 437-451.

[45] Looker, T.; Berry, C. L. The growth and development of the rat aorta II. Changes in nucleic acid and scleroprotein content. J. Anat., 1972, 113, 17-34

[46] Vogel, H. G. Species differences of elastic and collagenous tissueinfluence of maturation and age. Mech. Ageing Dev., 1991, 57, 1524.
[47] Lederle, F. A.; Johnson, G. R.; Wilson, S.E. Abdominal aortic aneurysm in women. J. Vasc. Surg., 2001, 34, 122-126.

[48] Scott, R. A. P.; Bridgewater, S. G.; Ashton, H. A.. Randomized clinical trial of screening for abdominal aortic aneurysm in women. Br. J. Surg., 2002, 89, 283-285.

[49] Witteman, C.; Grobbee, D. E.; Kok, F. J.; Hofman, A.; Valkenburg, H. A. Increased risk of atherosclerosis in women after the menopause. BMJ, 1989, 298, 642 .

[50] Cembrano, J.; Lillo, M.; Val, J.; Mardones, J. Influence of sex difference and hormones on elastine and collagen in the aorta of chickens. Circ. Res., 1960, 8, 527-529.

[51] Fischer, G. M.; Swain, M. L. Effect of sex hormones on blood pressure and vascular connective tissue in castrated and noncastrated male rats. Am. J. Physiol., 1977, 232, 617-21.

[52] Fischer, G. M.; Bashey, R.I.; Rosenbaum, H.; Lyttle, C.R. A possible mechanism in arterial wall for mediation of sex difference in atherosclerosis. Exp. Mol. Pathol., 1985, 43, 288-296.

[53] Fischer, G. M.; Swain, M. L. Effects of estradiol and progesterone on the increased synthesis of collagen in atherosclerotic rabbit aortas. Atherosclerosis, 1985, 54, 177-185.

[54] Dobrin, P. B.; Baker, W. H.; Gley, W. C. Elastolytic and collagenolytic studies of arteries: implications for the mechanical properties of aneurysms. Arch. Surg., 1984, 119, 405-409.

[55] Dobrin, P.B.; Mrkvicka, R. Failure of elastin or collagen as possible critical connective tissue alterations underlying aneurysmal dilatation. Cardiovasc. Surg., 1994, 2, 484-488.

[56] Whittle, M.A.; Hasleton, P.S.; Anderson, C. J. Collagen in dissecting aneurysms of human thoracic aorta. Increased collagen content and decreased collagen concentration may be predisposing factors in dissecting aneurysms. Am. J. Cardiovasc. Pathol., 1990, 3, 311319.

[57] Menashi, S.; Campa, J. S.; Greenhalgh, R. M.; Powell, J. T. Collagen in abdominal aortic aneurysm: typing, content, and degradation. J. Vasc. Surg., 1987, 6, 578-582.

[58] Rizzo, R. J.; McCarthy, W. J.; Dixit, S. N.; Lilly, M. P.; Shively, V.P.; Flinn, W.R.; Yao, J. S. Collagen types and matrix protein content in human abdominal aortic aneurysms. J. Vasc. Surg., 1989, 10, 365-373.

[59] Carmo, M.; Colombo, L.; Bruno, A.; Corsi, F. R. M.; Roncoroni, L.; Cuttin, M.S.; Radice, F.; Mussini, E.; Settembrini, P. G. Alteration of elastin, collagen and their cross-links in abdominal aortic aneurysms. Eur. J. Vasc. Endovasc. Surg., 2002, 23, 543-549.

[60] Borges, L. F.; Jaldin, R.G.; Dias, R.R.; Stolf, N. A. G.; Michel, J B.; Gutierrez, P. S. Collagen is reduced and disrupted in human aneurysms and dissections of ascending aorta. Hum. Pathol., 2008, 39, 437-443.

[61] Wolinsky, H. Long-term effects of hypertension on the rat aortic wall and their relation to concurrent aging changes. Morphological and chemical studies. Circ. Res., 1972, 30, 301-309.

[62] Ooshima, A.; Fuller, G. C.; Cardinale, G. J.; Spector, S.; Udenfriend, S. Increased collagen synthesis in blood vessels of hypertensive rats and its reversal by antihypertensive agents. Proc. Natl. Acad. Sci, 1974, 71, 301-3023.

[63] Bashey, R.I.; Cox, R.; McCann, J.; Jimenez, S.A. Changes in collagen biosynthesis, types, and mechanics of aorta in hypertensive rats. J. Lab. Clin. Med., 1989, 113, 604-611.

[64] Belmin, J.; Juan, L.; Tedgui, A. Water, DNA and collagen content in different parts of rat aorta. Effect of hypertension. Arch. Mal. Coeur. Vaiss., 1990, 83, 1305-1307.

[65] Castro, M.M.; Rizzi, E.; Figueiredo-Lopes, L.; Fernandes, K.; Bendhack, L.M.; Pitol, D.L.; Gerlach, R.F.; Tanus-Santos, J.E. Metalloproteinase inhibition ameliorates hypertension and prevents vascular dysfunction and remodeling in renovascular hypertensive rats. Atherosclerosis, 2008, 198, 320-331.

[66] Ceron, C. S.; Rizzi, E.; Guimaraes, D.A.; Martins-Oliveira, A.; Cau, S. B.; Ramos, J.; Gerlach, R. F.; Tanus-Santos, J. E. Time course involvement of matrix metalloproteinases in the vascular alterations of renovascular hypertension. Matrix Biol., 2012, 31, 261270.

[67] Clerc, C. P.; Renaud, J. F.; Blacher, J.; Legrand, M.; Samuel, J. L.; Levy, B. I.; Sassard, J.; Safar, M. E. Collagen I and III and mechanical properties of conduit arteries in rats with genetic hypertension. J. Vasc. Res., 1999, 36, 139-146.

[68] Herrmann, J.; Samee, S.; Chade, A.; Porcel, M. R.; Lerman, L. O.; Lerman, A. Differential effect of experimental hypertension and 
hypercholesterolemia on adventitial remodeling. Arterioscler

Thromb Vasc. Biol., 2005, 25, 447-453.
[69] McNulty, M.; Mahmud, A.; Spiers, P.; Feely, J. Collagen type-1 degradation is related to arterial stiffness in hypertensive and normotensive subjects. J. Hum. Hypertens., 2006, 20, 867-873.

(C) Panagiotis Berillis; Licensee Bentham Open.

This is an open access article licensed under the terms of the Creative Commons Attribution Non-Commercial License (http://creativecommons.org/licenses/by-nc/3.0/) which permits unrestricted, non-commercial use, distribution and reproduction in any medium, provided the work is properly cited. 